\title{
Physician understanding and application of surrogate decision-making laws in clinical practice
}

\author{
Amber Rose Comer a , Margaret Gaffney ${ }^{\mathrm{b}}$, Cynthia L. Stone ${ }^{\mathrm{c}}$, and Alexia Torke ${ }^{\mathrm{d}}$ \\ ${ }^{\mathrm{a}}$ Indiana University School of Health and Rehabilitation Sciences; ${ }^{\mathrm{b}}$ Indiana University School of \\ Medicine; ${ }^{\mathrm{c}}$ Department of Health Policy and Management, Indiana University School of Public Health; ${ }^{\mathrm{d}}$ \\ Indiana University School of Medicine
}

\begin{abstract}
Background: Although state surrogate laws are the most common way surrogate decision makers are identified, no studies have been conducted to determine physician understanding of these laws or how these laws are utilized during clinical practice. The purpose of this study is to better understand how surrogate decision-making laws function in practice. Methods: A cross-sectional survey of 412 physicians working in Indiana hospitals was conducted between November 2014 and January 2015 to determine physicians’ knowledge of Indiana’s surrogate decision-making law and physicians’ approaches to hypothetical cases using the law in clinical practice. Results: Fewer than half of physicians (48\%) were able to correctly identify all legally allowable surrogate decision makers. Of those physicians who knew the law, nearly all of them (98\%) indicated that they would violate the law during clinical practice by allowing non-legal surrogates such as grandchildren to make medical decisions. Conclusions: A majority of physicians endorse relying on surrogates who have strong ties to the patient but are not legally allowable in Indiana. It is possible that these decisions reflect sound ethical reasoning even though they are illegal. Due to the narrow construction of some state surrogate decision laws, physicians may be placed in the position where they must either choose to follow medical ethical principles or the law. To alleviate these issues, state surrogate decision laws need to be amended to include a broader list of surrogates, such as extended family and close friends.
\end{abstract}

Keywords: empirical research; bioethics; health policy; policy analysis

This is the author's manuscript of the article published in final edited form as:

Comer, A. R., Gaffney, M., Stone, C. L., \& Torke, A. (2016). Physician understanding and application of surrogate decision-making laws in clinical practice. AJOB Empirical Bioethics.

https://doi.org/10.1080/23294515.2016.1234520 
When a patient in a hospital is medically incapacitated and unable to make decisions for him or herself, a surrogate decision maker is required to make decisions about the patient's care in proxy. Surrogate decision makers are identified in three ways: (1) appointment by the patient prior to incapacitation via a health care power of attorney document or health care surrogate form; (2) a court guardianship order; or (3) a default state surrogate decision-maker law (Correria 2012; Glatzer 2005). Each state is charged with creating its own laws regarding who is qualified to serve as a surrogate decision maker; thus, who may serve as a surrogate decision maker varies throughout the country (Bravo 2008; Taylor 1999). In the absence of an advance directive or available surrogate under state law, any person desiring to serve as a proxy for the incapacitated patient must obtain a legal guardianship through the court in order to serve as a surrogate decision maker (Quinn 2009; Radford 2001). Obtaining a legal guardianship is rarely done as it is time-consuming, costly, and emotionally taxing on the potential surrogate (Beauchamp 2009; Buchanan 1990; Herr 1994; Pope 2013). This may leave some patients without a legally authorized decision maker, even though they have friends or family members willing to serve as a surrogate.

Much of what is known about surrogate decision making focuses on the advance directive, a document by which the patient appoints the surrogate prior to incapacitation (Butler 2015; Buchanan 1990). Prior research in this area has focused on the utilization of advance directives (Butler 2015) or on the population of patients who are "un-befriended," which are patients without any appropriate legal surrogate (Herr 1994). However, studies show that fewer than $20 \%$ of patients in hospitals present with a designated health care surrogate appointed by the patient or court, meaning that the overwhelming majority of surrogates in hospitals are identified via default state statutes (Areen 2007; Houben 2014; Portman 1991). Although state surrogate laws are the most common way that surrogate decision makers are identified in inpatient hospital units and emergency departments, no studies have been conducted to determine physician understanding of these laws or how these laws are used in clinical practice. 
The purpose of this study is to better understand how surrogate decision-making laws function in practice in one state that limits surrogate decision making to first-degree relatives. This study explores the extent to which physicians understand state laws regarding who may serve as a legal surrogate and examines how physicians interpret surrogate laws in hypothetical scenarios. This study is important to hospital administrators, physicians, and state lawmakers and policymakers because it sheds light on physicians' knowledge of the law and how they are likely to use these laws in clinical practice.

\section{Methods}

A statewide, cross-sectional survey of physicians working in Indiana hospitals was conducted between November 2014 and January 2015 to determine physicians’ knowledge of Indiana’s surrogate decision making law and physicians’ approaches to hypothetical cases related to using the law in clinical practice.

\section{Survey Design}

The survey was designed based on a review of the relevant literature and was reviewed for face validity by content experts in surrogate decision making research, including physicians, attorneys, nurses, and other health care professionals. Then, feedback regarding question clarity, choice of words, missing items, and length was obtained during the survey pretest from a convenience sample of 40 physicians from our local health system.

In order to measure physician understanding of the law, the survey included questions that asked the physician to indicate (1) who qualifies as an appropriate surrogate under Indiana law (Herr 1994); (2) who is the appropriate final decision maker in the event that there are multiple legal decision makers in disagreement over patient care; and (3) the appropriate next step if no legal surrogate is available. In order to measure whether physicians adhere to the law in practice while treating patients, physicians were presented with four hypothetical vignettes (see appendix). Each vignette was designed to measure whether physicians would allow a potentially ethically appropriate but legally inappropriate surrogate under 
Indiana law to make the patient's medical decisions (Quinn 2009). Each vignette was followed by a question with a yes/no response (Figure 1).

This survey protocol was approved by the Indiana University Institutional Review Board.

\section{Survey Sample}

Utilizing the 2014 Physician Masterfile of the American Medical Association (AMA), all physicians who work in the inpatient clinical setting within the state of Indiana were identified based on specialty (Table 1). Pediatricians and pediatric sub-specialties were excluded due to their patient population consisting of minors, who fall under a different surrogate decision-making protocol than adults. Pathologists and radiologists who did not have direct patient contact were excluded. From the resulting 1444 physicians, the AMA randomly selected a total sample of 1200 physicians.

\section{Survey administration}

Surveys were sent via U.S. postal mail. Starting in November 2014 and ending in January 2015, three survey distribution waves were utilized, with the waves mailed approximately 1 month apart. The first two waves included a cover letter, a paper copy of the survey, and a self-addressed postage-paid envelope. Additionally, the first wave included a \$5 Starbucks gift card that the physicians were informed they could keep regardless of whether they completed the survey. The third wave consisted of a postcard that reminded physicians either to return the paper survey or take the survey online. Online surveys were administered via REDCap, an electronic survey plat-form accessed via an online link provided on the postcard (Harris 2001). Each survey was individually labeled with a subject identification number to allow tracking of non-respondents. Upon receipt of completed surveys all data were entered and stored in REDCap.

\section{Statistical analysis}


Descriptive analyses were performed in order to determine physicians' knowledge of the law and whether they follow the law in practice, shown as relative frequencies and percentages from the total sample size. Chi-squared analysis was conducted in order to determine demographic predictors of physician understanding of the law. Results are presented as a percentage of the total number of study participants. All p values were two-tailed. Analytic assumptions were tested and verified. All analyses were performed using SAS version 9.4 (SAS Institute, Cary, NC).

\section{Results}

In total, 412 physicians completed the questionnaire, yielding an overall response rate of $34.33 \%$. The characteristics of physicians who responded to the questionnaire are represented in Table 1 . There were 303 males (73.54\%) and 109 females (26.46\%); these numbers are representative of the male to female ratio of practicing physicians in the state of Indiana (69.94\% male, 29.24\% female) (Kaiser 2016). The largest number of respondents indicated that their medical specialty was family medicine 70 (16.99\%) and emergency medicine 70 (16.99\%). The majority of physician respondents 229 (55.66\%), indicated that they have practiced medicine for greater than 20 years. There were not statistically significant differences between physicians who answered each of the three legal questions correctly (Table 1).

Overall, fewer than half of physicians, 198 (48.06\%), were able to correctly answer all items regarding who qualifies as a legally allowable surrogate decision maker under Indiana law (spouse, adult child, parent, and adult sibling). Only 61 (14.81\%) of the physicians correctly answered that Indiana provides equal decision-making authority to all appropriate surrogates under the law. More than half (237 or 57.52\%) of physicians were able to identify that pursuing a guardianship ruling is the appropriate legal action in the event of an irreconcilable dispute between family members about an incapacitated patient's plan of care (Table 2). Table 3 shows the frequency with which physicians indicated that they believed each surrogate was legally allowable. We found that $19.9 \%$ of physicians thought civil partners were legally authorized surrogates and $16.5 \%$ thought grandchildren were. 
When presented with clinical vignettes, nearly all physicians 348 (84.47\%) reported that they would allow a grandchild to act as a surrogate decision maker, 149 (36.17\%) of physicians would allow unmarried same-sex partners (the survey was administered prior to Obergefell $v$. Hodges, the Supreme Court decision making same sex marriage legal in the United States), 58 (14.08\%) would allow close friends, and 162 (39.32\%) would allow unmarried long-term partners, even though all such relationships are excluded as per-mitted guardians under state law (Table 4).

Of those physicians who were able to correctly identify all legal decision makers (i.e., physicians who indicated that grandchildren are not legally appropriate surrogates under the law), nearly all of them 183 (92.42\%) stated they would allow grandchildren to serve as surrogates in a clinical vignette.

Additionally, of those same physicians, 82 (41.41\%) indicated they would allow same-sex partners to serve as surrogates in practice, 39 (19.70\%) would allow close friends to serve as surrogates in practice, and 80 (40.40\%) would allow unmarried long-term partners to serve as surrogates in practice (Table 4).

\section{Discussion}

This study of physician knowledge and case vignettes shows that the majority of physicians do not accurately identify the types of relationships that confer legal authority to potential surrogate health care decision makers under Indiana law. In other words, physicians in this sample do not appear to understand a law that they are legally tasked with obeying. Under the law, potential surrogates should be disqualified if "in the good faith opinion of the attending physician" the surrogate is not qualified to make decisions (Medical Consent Law 2016).

Among those physicians who were able to correctly identify legally appropriate surrogates, almost all would violate the law in practice by allowing one or more surrogates to make decisions when they are not authorized by law. For example, when confronted with a grandchild as a potential surrogate decision maker, $92.42 \%$ of physicians who correctly identified that grandchildren are not legally allowable surrogates indicated that in practice they would confer authority for health care decision 
making for an incapacitated patient to a grandchild. This pattern is similar for other non-legal surrogates: 41.41\% of physicians would allow same-sex partners; $16.69 \%$ of physicians would allow close friends; and $40.40 \%$ of physicians would allow unmarried long-term (common-law) partners (Table 4). In each case, physicians who correctly identified surrogates under the law were more likely to allow non-legal surrogates to engage in a decision-making role in clinical practice.

There are several possible explanations for why physicians indicated that they would allow surrogates who are not legally appropriate to make decisions for patients. First, some physicians simply do not know the law. This is evidenced by the data demonstrating that less than half of physicians were able to correctly identify all appropriate legal surrogates. A lack of physician knowledge of the law could be addressed with more physician education. However, while it is tempting to explain away the high numbers of physicians who allow grandchildren to act as surrogates in practice as naiveté in terms of the law, only $16.50 \%$ of all physicians (whether or not they were able to correctly identify all legally appropriate surrogates) indicated that they believed grandchildren were legally appropriate surrogates (Table 2). The vast difference in the number of physicians who allow grandchildren to act as surrogates in practice and the number of physicians who indicated that they thought grandchildren were legally allowable surrogates cannot be explained by a lack of understanding the law alone.

Perhaps physicians believe that the decision to allow a grandchild to make surrogate decisions is ethically appropriate, despite the law. Ethical principles informing surrogate decision making ask surrogates to base decisions on the patient's preferences and values, including how the patient viewed life and how he or she wanted to live his or her life, and the patient's attitude toward illness, pain, suffering, and medical procedures (Taylor 1999). Physicians may believe that a grandchild, unmarried partner, or other individual close to the patient is able to meet that ethical standard. Whether or not this is the case is difficult to ascertain from a quantitative survey; however, the data show that this explanation is plausible. As evidenced by the data, many physicians who know the law would still allow a loving, caring person 
who seems to know the patient and have the patient's best interest in mind to act as a surrogate regardless of his or her relationship to the patient.

Each hypothetical vignette was designed to present physicians with an ethically defensible but legally inappropriate surrogate (Buchanan 1990; Beauchamp 2009). While this study does not reveal the number of times that physicians base their decisions on ethical principles, it can be reasoned that not all physicians who violate the law do so in the interest of ethical principles. If a physician allowed all persons who fit the ethical definition of a surrogate to act as the surrogate, then there would not be such a discrepancy between the number of physicians who violate the law in order to allow grandchildren to act as surrogates (92.42\%) and those who allow close friends (19.69\%) to make decisions. The numbers would be much closer if bioethical principles were strictly applied because each of the proposed surrogates could be considered appropriate under ethical standards. However, whether physicians are truly making these decisions based on ethical principles requires further study.

An alternative explanation is that some physicians may sim-ply allow the most convenient surrogate to make decisions for the patient. Regardless of physician's knowledge of the law, a large number of physicians indicated through the survey questions that they would allow the seemingly only available person at the patient's bedside to serve as the surrogate regardless of the surrogate's relationship to the patient. Admittedly, in all of these cases, it is easier to allow the surrogate at the bedside to make the decisions than to inform the surrogate that they are not legally appropriate. In each situation, disqualifying the surrogate at the bedside would delay appropriate patient care until the person who wishes to serve as the surrogate could obtain a guardianship ruling through the courts. In practical terms, if only one person is available at the patient's bedside, it is unlikely that physicians will question the legality of their surrogacy due to concerns about legal or other issues that might arise and create conflict.

This study has several limitations. First, because the study used hypothetical vignettes, it may not accurately reflect who physicians would choose as a surrogate in practice. Physicians may over-or underestimate the extent to which they would actually seek out the legal surrogate in clinical practice. 
This may introduce bias in the responses. Further research is needed to compare knowledge of the law with clinical practice. Second, this study does not measure factors related to the reasons physicians allow certain legally inappropriate surrogates to serve. Third, the population only includes physicians practicing in the state of Indiana, and thus the results may not apply to physicians practicing in other states. These limitations require further study in order to gain a broader picture of the surrogate decision-making process.

The results of this study may have implications for the way state surrogate decision-making laws are formulated. It is clear that physicians are not following the law in many instances in their effort to deliver care to patients. The reasons that physicians are ignoring surrogate decision-making laws requires further study. However, regardless of the reasons, this study shows that physicians either do not understand or do not agree with the law in practice. An alternative solution would be to amend state surrogate decision-making laws in order to better include close friends and family who are likely to serve as surrogate decision makers and whose participation is regarded as appropriate by many practicing physicians.

\section{Conclusion}

Physicians are the health care professionals legally responsible for identifying incapacitated patients’ surrogate decision makers. A majority of physicians endorse relying on surrogates who have strong ties to the patient but are not legally allowable in Indiana. It is possible that these decisions reflect sound ethical reasoning even though they are illegal. Due to the narrow construction of some state surrogate decision laws, physicians may be placed in the position where they must choose to follow either medical ethical principles or the law. To alleviate these ethical issues, state surrogate decision laws need to be amended to include a broader list of surrogates, such as extended family and close friends.

\section{Acknowledgments}


We express our gratitude and thanks to Amy R. Chamness and Rose Howard for assistance with survey administration.

\section{Author contributions}

Each author contributed to the conception, design, data, collection and editing of the manuscript.

\section{Funding}

This work was supported by the Charles Warren Fairbanks Center for Medical Ethics and the Indiana University Center for Aging Research.

\section{Conflicts of interest}

None.

\section{Ethical approval}

This study was approved by the institutional review board(s) at Indiana University. 


\section{References}

Areen, J. 2007. Advance directives under state law and judicial decisions. Journal of Law, Medicine \& Ethics 19(1-2): 91-100.

Beauchamp, T. L., and J. F. Childress. 2009. Principles of biomedical ethics, 7th ed. Oxford, UK: Oxford University Press.

Bravo, G., M. F. Dubois, and B. Wagneur. 2008. Assessing the effectiveness of interventions to promote advance directives among older adults: A systematic review and multi-level analysis. Social Science \& Medicine 67(7): 1122-32.

Buchanan, A. E., and D. W. Brock. 1990. Deciding for others: The ethics of surrogate decision making. Cambridge, UK: Cambridge University Press.

Butler, J., Z. Binney, A. Kalogeropoulos, et al. 2015. Advance directives among hospitalized patients with heart failure. JACC: Heart Failure 3(2): 112-21.

Correria, E. D. 2012. Why Rhode Island needs default surrogate consent Statutes. RI Bar Journal 60(5): $11-43$.

Glatzer, R. K. 2005. Equality at the end: Amending state surrogacy statutes to honor same-sex couples’ end-of-life decisions. Elder Law Journal 13 (255): 255-82.

Gordy, S., and E. Klein. 2011. Advance directives in the trauma intensive care unit: Do they really matter? International Journal of Critical Illness \& Injury Science 1(2): 132-37.

Harris, P.A., R. Taylor, R. Thielke, J. Payne, N. Gonzalez, and J. G. Conde. 2009. Research electronic data capture (REDCap) — A Meta- data-driven methodology and workflow process for providing translational research informatics support. Journal of Biomedical Informatics 42(2): 377-81. 
Health Care Consent. 1993. In Indiana Code: 16-36-1-5. Available at: https://iga.in.gov/staticdocuments/3/e/8/1/3e816a67/TITLE16_AR36_ch1.pdf

Herr, S. S., and B. L. Hopkins. 1994. Health care decision making for per- sons with disabilities. An alternative to guardianship. Journal of the American Medical Association 271(13): 1017-22.

Houben, C. H., M. A. Spruit, M. T. Groenen, et al. 2014. Efficacy of advance care planning: A systematic review and meta-analysis. Journal of the American Medical Directors Association 15(7): 477-89.

Indiana Medical Consent Act. 2016. Indiana Code 16-36-1-4. Available at: https://iga.in.gov/staticdocuments/3/e/8/1/3e816a67/TITLE16_AR36_ ch1.pdf

Kaiser Family Foundation. 2016. Distribution of physicians by gender. Available at: http://kff.org/other/state-indicator/physicians-by-gender (accessed August 29, 2016).

Lo, B. 2013. Resolving ethical dilemmas: A guide for clinicians, 5th ed. Philadelphia, PA: Wolters Kluwer.

Pope, T. M. 2013. Making medical decisions for patients without surrogates. New England Journal of Medicine 369(21): 1976-78.

Portman, R. M. 1991. Surrogate decision-making legislation: The next frontier in life-sustaining treatment policy. American Health Lawyers Association Journal of Health Law 24(10): 311.

Quinn, M.J. 2009. Guardianships of adults. In Wiley encyclopedia of forensic science. Hoboken, NJ: John Wiley \& Sons, Ltd. http://onlinelibrary.wiley.com/doi/10.1002/9780470061589.fsa485/full

Radford, M. F. 2001. Advantages and disadvantages of mediation in pro- bate, trust, and guardianship matters. Pepperdine Dispute Resoution Law Journal 1(241): 241-54.

Taylor, J. S., D. K. Heyland, and S. J. Taylor. 1999. How advance directives affect hospital resource use: Systematic review of the literature. Canadian Family Physician 45: 2408-13. 
Table 1. Physician Characteristics and Association of Knowledge of the Law

\begin{tabular}{lrll}
\hline Item & $\mathrm{N}(\%)$ & $\begin{array}{l}\text { Correct Knowledge of } \\
\text { the Law }\end{array}$ & p-value \\
\hline Medical Specialty & $70(16.99)$ & $32(45.71)$ & .3747 \\
$\quad$ Family Medicine & $70(16.99)$ & $34(48.57)$ & \\
Emergency Medicine & $43(10.44)$ & $20(46.51)$ & \\
Anesthesiology & $41(09.95)$ & $27(65.85)$ & \\
$\quad$ Inpatient Internal Medicine & $40(09.71)$ & $15(37.50)$ & \\
$\quad$ Surgery and Surgical & & & \\
Subspecialties & $13(03.16)$ & $4(30.77)$ & \\
Gynecology & $11(02.67)$ & $3(27.27)$ & \\
Cardiology & $11(02.67)$ & $8(72.73)$ & \\
Oncology & $8(01.94)$ & $2(25.00)$ & \\
Intensive Care & $7(01.70)$ & $6(85.71)$ & \\
Palliative Care & $5(01.21)$ & $3(60.00)$ & \\
Pulmonology & $4(00.97)$ & $2(50.00)$ & \\
Neurology & $3(00.73)$ & $3(100.00)$ & \\
Geriatrics & $1(00.24)$ & $1(100.00)$ & \\
Nephrology & $85(20.63)$ & $38(44.71)$ & \\
Other & & & .41938 \\
Years as a Licensed Physician & $47(11.57)$ & & \\
$0-10$ & $136(32.77)$ & & \\
11 - 20 & $229(55.66)$ & & \\
> 20 & & & \\
Gender & $303(73.54)$ & & \\
Male & $109(26.46)$ & & \\
Female & &
\end{tabular}


Table 2. Physician Knowledge of Law

\begin{tabular}{lr}
\hline Item & $\mathrm{N}(\%)$ \\
\hline Physicians with accurate knowledge of the law & $198(48.06)$ \\
Physicians who correctly identified that there is no hierarchy of decision & $61(14.81)$ \\
makers & \\
$\begin{array}{l}\text { Physicians who identified that pursing a guardianship is the correct legal } \\
\text { action in the event of an irreconcilable dispute between family members }\end{array}$ & $237(57.52)$ \\
\hline
\end{tabular}


Table 3. Frequency Physician Believed Surrogate was Legal*

\begin{tabular}{lc}
\hline Item & $\mathrm{N}(\%)$ \\
\hline Spouse & $409(99.27)$ \\
Adult Child & $324(78.64)$ \\
Parent & $305(74.03)$ \\
Adult Sibling & $204(49.51)$ \\
Civil Partner & $82(19.90)$ \\
Grandchild & $68(16.50)$ \\
Close Friend & $21(05.10)$ \\
Live in Boyfriend/ Girlfriend & $20(04.85)$ \\
\hline *Under Indiana law, spouses, parents, adult children, and adult siblings are legal surrogate decision makers.
\end{tabular}


Table 4. Association between physician's knowledge of the surrogate law and who physicians allow to serve as surrogates in practice

\begin{tabular}{llcc}
\hline $\begin{array}{l}\text { Who physicians allow to serve as } \\
\text { surrogates in clinical practice }\end{array}$ & $\begin{array}{l}\text { All physicians } \\
\mathrm{N}(\%)\end{array}$ & $\begin{array}{l}\text { Physicians with correct } \\
(n=412)\end{array}$ & $\begin{array}{c}\text { knowledge of law } \\
\mathrm{N}(\%)(n=179)\end{array}$ \\
\hline Grandchildren & $348(84.47)$ & $183(92.42)$ & .0008 \\
Unmarried/ Common Law & $162(39.32)$ & $82(41.41)$ & .5297 \\
Partner & & & \\
Same-Sex Partners & $149(36.17)$ & $80(40.40)$ & .0209 \\
Close Friend & $58(14.08)$ & $39(19.69)$ & .1862 \\
\hline
\end{tabular}


Figure 1. Vignettes which measured whether physicians would allow a potentially ethically appropriate, but legally inappropriate surrogate under the law to act as a patient's surrogate medical decision maker.

1. Your patient is an elderly widow whose only child has died. Her granddaughter has been taking care of her for the past five years and is always present at the bedside. Your patient needs a procedure which Yes $\square$ No requires informed consent. Would you allow the granddaughter to consent to the procedure?

2. Your patient is a gay man who is estranged from his family. His partner of twenty years and several friends are present at the bedside. Your patient's parents are aware that their son is in the hospital but have no interest in visiting. Your patient's partner would like to change the patient's code status to DNR. Would you change the code status?

3. A homeless patient is unconscious after a drug overdose. He does not have any family that can be identified. A man in the patient's room identifies himself as the patient's best friend, but says they are the only family each other has and says they call each other brothers. It is clear that the patient and his friend have a very close and caring relationship. The patient's friend claims that he and the patient have "spoken about what the patient would want done if he overdosed on drugs again." Would you allow the patient's friend to make the patient's medical decisions?

4. Your patient is a sixty year old woman who has two adult children. Since her divorce twenty years ago, she has lived with her boyfriend and has had very little contact with her children who both live out of Yes $\square \quad$ No $\square$ state. The patient's long term boyfriend is present at the bedside and insists that he and the patient are married under common law because they have lived together for twenty years. The patient is in a medically induced coma and needs a simple procedure which requires informed consent. Would you allow the patient's boyfriend to give consent on behalf of the patient?

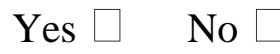


Appendix: Physician Surrogate Decision Making Survey 


\section{Physician Surrogate Decision Making Survey}

\section{Section A: For each question select all responses that apply.}

1. An adult patient is incapacitated and unable to make his/her own medical decisions. The patient has not completed a health care power of attorney or health care representative form. Which of the following people are permitted to make medical decisions for the patient under Indiana law? Check all that apply.

Spouse

Adult children

Civil partner

Live-in boyfriend/girlfriend

Parent

Adult sibling

Niece/ nephew

Grandchild

Close friend

2. In the event of a dispute between family members about an incapacitated patient's plan of care, which of the following family members has the final decision making authority under Indiana law?

Spouse

Adult Children

Parent

Adult Siblings

Spouse and adult children share equal decision making authority

Spouse and parents share equal decision making authority

All of these family members share equal decision making authority

3. In the event of a dispute between legal surrogate decision makers about an incapacitated patient's plan of care, what action must the family take in order to legally specify one ultimate decision maker?

Settle the dispute among the family

Pursue a guardianship through the courts

Go to mediation

This question is not valid in Indiana because there is only one ultimate surrogate decision maker as specified by the Indiana surrogate decision making statute. 
Section B: For each question assume the following:

- Each patient has NOT executed a health care power of attorney or health care representative form;

- Each patient is located within the state of Indiana; and

- Each patient is an incapacitated adult and unable to make his or her own medical decisions.

\section{PLEASE ANSWER THESE QUESTIONS AS YOU WOULD OR HAVE ACTED DURING PRACTICE.}

1. Your patient is an elderly widow whose only child has died. Her granddaughter has been taking care of her for the past five years and is always present at the bedside. Your patient needs a procedure which requires informed consent. Would you allow the granddaughter to consent to the procedure?

2. Your patient is a gay man who is estranged from his family. His partner of twenty years and several friends are present at the bedside. Your patient's parents are aware that their son is in the hospital but have no interest in visiting. Your patient's partner would like to change the patient's code status to DNR. Would you change the code status?

3. A homeless patient is unconscious after a drug overdose. He does not have any family that can be identified. A man in the patient's room identifies himself as the patient's best friend, but says they are the only family each other has and says they call each other brothers. It is clear that the patient and his friend have a very close and caring relationship. The patient's friend claims that he and the patient have "spoken about what the patient would want done if he overdosed on drugs again." Would you allow the patient's friend to make the patient's medical decisions?

4. Your patient is a sixty year old woman who has two adult children. Since her divorce twenty years ago, she has lived with her boyfriend and has had very little contact with her children who both live out of state. The patient's long term boyfriend is present at the bedside and insists that he and the patient are married under common law because they have lived together for twenty years. The patient is in a medically induced coma and needs a simple procedure which requires informed consent. Would you allow the patient's boyfriend to give consent on behalf of the patient? 


\section{Section C: Answer each question as best as you can remember.}

1. In the last year, how many times have you experienced a delay in patient care because you could not properly identify a surrogate decision maker?

No delay

$1-3$ times

$4-6$ times

$>7$

2. What is the longest a patient's care was delayed?

No delay

$<1$ day

1 day

$2-3$ days

$>4$ days
3. Where have you experienced these delays in patient care? Check all that apply.
Inpatient

Inpatient ICU

Outpatient

4. In the past year, how many times have you experienced a delay in a patient's care because the patient had more than one surrogate decision maker and the surrogate decision makers did not agree on the patient's course of treatment?

No delay

$1-3$ times

$4-6$ times

$>7$ times

5. What is the longest a patient's care was delayed?

No delay

$<1$ day

1 day

$2-3$ days

$>3$ days
6. Where have you experienced these delays in patient care? Check all that apply.
Inpatient Inpatient ICU

Outpatient

\section{Case Manager}

Co-Worker

Ethics Consultant

Legal Department

Social Work

Other:

N/A 
Section D: Demographic Information

1. What is your medical specialty? 
Anesthesiology

Cardiology

Emergency medicine

Family Medicine

Geriatrics

Gynecology
Inpatient internal medicine Intensive care

Nephrology

Neurology

Oncology

Palliative care
Pulmonology

Surgery and surgical subspecialties

Other:

2. What is your current professional status?

Attending

Fellow

Resident

Other:

3. In what clinical setting do you practice? Check all that apply.

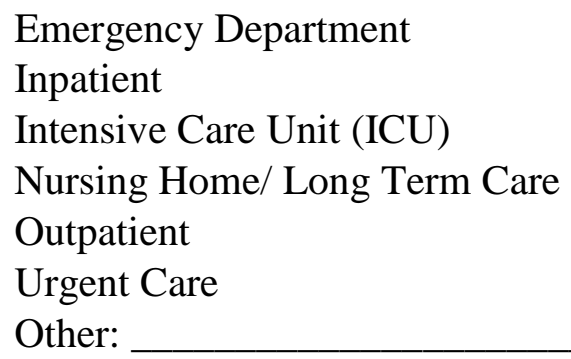

Inpatient

Intensive Care Unit (ICU)

Nursing Home/ Long Term Care

Outpatient

Urgent Care

Other:

4. How many years have you been a licensed physician?

$0-10$

$10-20$

$>20$

5. What is your gender?

Male

Female

6. What is your race? Check all that apply.

White

Black or African American

American Indian or Alaska Native

Asian (Includes South Asia)

Native Hawaiian or Other Pacific Islander

Hispanic/ Latino

Choose not to respond 